Article

\title{
Optimization of the Microwave-Assisted Extraction Process of Bioactive Compounds from Annatto Seeds (Bixa orellana L.)
}

\author{
Julian Quintero Quiroz ${ }^{1, *}$, Angélica Celis Torres ${ }^{1}$, Luisa Muñoz Ramirez ${ }^{1}$, \\ Mariluz Silva Garcia ${ }^{2}$, Gelmy Ciro Gomez ${ }^{1}$ and John Rojas Camargo ${ }^{1}$ \\ 1 College of Pharmaceutical and Food Sciences, University of Antioquia, Calle 67 No. 53-108, \\ University Campus, Medellín 050010,Colombia; angelica.celis@udea.edu.co (A.C.T.); \\ luisa.munozr@udea.edu.co (L.M.R.); gelmy.ciro@udea.edu.co (G.C.G.); jhon.rojas@udea.edu.co (J.R.C.) \\ 2 Institute of Food Science and Technology (INTAL), Cra. 50g \#12S-91, Itagüi 055412, Colombia; \\ marisylva87@gmail.com \\ * Correspondence: julian.quintero@udea.edu.co; Tel.: +57-421-965-91
}

Received: 6 December 2018; Accepted: 31 January 2019; Published: 6 February 2019

\begin{abstract}
This study deals with the extraction, optimization, and evaluation of the antioxidant and antimicrobial activities of bioactive compounds obtained from the seeds of annatto using microwave-assisted extraction as compared to leaching. Annatto seeds were subjected to a microwave treatment of $2450 \mathrm{MHz}$ and power of 700 watts using a response surface design involving four factors: $\mathrm{pH}$ (4-11), solvent concentration (ethanol) (50-96\%), solvent-to-seed ratio (2-10), and microwave exposure time ( $0-5 \mathrm{~min})$. The contents of polyphenol compounds and bixin were taken as response variables. Subsequently, the antioxidant and antimicrobial activities were assessed at the optimal processing conditions predicted by the experimental design. Microwaves, solvent concentration, and the solvent-to-seed ratio showed a statistically significant effect for the extraction of polyphenol compounds and bixin. Thus, microwaves accelerated the extraction of those compounds and the slight increase in temperature caused some degradation of the polyphenol compounds. The microwave-assisted extraction increased the contents of polyphenols and bixin along with their antioxidant activity as compared to leaching extraction. However, this technique does not significantly improve the antimicrobial activity against Bacillus cereus and Staphylococcus aureus.
\end{abstract}

Keywords: antimicrobial activity; antioxidant activity; polyphenol compounds; bixin

\section{Introduction}

The reddish or orange extract obtained from the seeds of annatto (Bixa orellana L.) has a great coloring strength, making this extract useful in the food and cosmetic sectors. In addition, the extract possesses inflammatory, antioxidant, and antimicrobial properties [1,2]. These pharmacological activities are due to diverse bioactive compounds such as polyphenols (i.e., hypolatin and caffeic acid) and carotenoids (i.e., bixin or 6-methyl hydrogen (9Z)-6,6'-diapocarotene-6) [3]. The antioxidant activity of these compounds is attributed to their high structural conjugation and capability to couple with singlet oxygen which is responsible for denaturation of proteins belonging to cell membranes, leading to cell lysis $[1,4,5]$.

Recent reports deal with the biological activity of annatto extract obtained by traditional techniques, which are compelling for the pharmaceutical and food companies. For instance, Zhang and collaborators assessed the ability of bixin to promote transcription of a new Ets-related factor (Nrf2) and E74-like factor 2 (ELF2) in a murine model with inflammation in the lung tissue due to $\mathrm{SiO}_{2}$ particles. This transcription factor regulates the inducible expression of numerous genes of detoxifying 
enzymes and antioxidants by binding to a specific DNA sequence known as the antioxidant response element (ARE), resulting in protection against several pathologies such as cancer, liver toxicity, and inflammation [6]. Further, the activation of Nrf2 in mice potentiates the antioxidant and healing abilities and decreased lung tissue inflammation after inhalation of bixin particles [2]. On the other hand, Viuda and collaborators determined the in vitro antioxidant and antimicrobial activities of annatto seed extract. They used five different hydrogen-donating or radical-scavenging tests including the 2,2'-diphenyl-1-picrylhydrazyl (DPPH) stable radical, ferric-reducing antioxidant power (FRAP), thiobarbituric acid reactive substance (TBARS), Rancimat, and ferrous ion ( $\mathrm{Fe}^{2+}$ ) chelating activity. On the other hand, the microdilution in broth method was used to evaluate the antimicrobial activity against Listeria innocua (Spanish Type Culture Collection, University of Valencia, Research Building, Burjassot, Spain. (CECT) 910), Aeromonas hydrophila (CECT 5734), Bacillus cereus (American Type Culture Collection (ATCC) 11778), and Pseudomona aeruginosa (ATCC 9027). They found the annatto seed extract as an alternative preservative to replace the synthetic ones such as butyl-hydroxy toluene (BHT) in food matrices due to its extensive antioxidant activity $(93.01 \pm 1.22,75.88 \pm 0.21,25.41 \pm 3.52$, $10.53 \pm 0.31$, and $1.34 \pm 0.07$ for DPPH (inhibition, \%), TBARS (inhibition, \%), FRAP (TEAC), FIC (chelating effect, \%), and rancimat (AAI), respectively. Conversely, it had a mild antimicrobial action compared to some synthetic antimicrobials $(1.024 \mathrm{mg} / \mathrm{mL}, 256 \mathrm{mg} / \mathrm{mL}, 512 \mathrm{mg} / \mathrm{mL}$, and $256 \mathrm{mg} / \mathrm{mL}$ for P. aeruginosa, B. cereus, L. innocua, and A. hydrophila, respectively) [1].

Maceration, leaching, extraction with supercritical fluids $\left(\mathrm{CO}_{2}\right)$, dispersive liquid-liquid, sonication, enzymatic extraction, microextraction, and microwave-assisted extraction (MAE) are the most widely used methods for the extraction of bioactive molecules from plants [7]. However, the extraction technique affects the functional activities of the extract and thus, conventional approaches require long processing times, exposing the active compounds to degradation and resulting in low efficiency. On the other hand, some emerging extraction techniques such as supercritical $\mathrm{CO}_{2}$ extraction are costly and involve high energy consumption [8]. Further, the use of mechanical methods, spouted bed, sonication, microwaves, and supercritical fluids $\left(\mathrm{CO}_{2}\right)$ as emerging extraction technologies, have been focused simply on the extraction of bixin and norbixin [7,9-11]. Most of these studies highlight the coloring capacity of the extract, and others evaluate the effect of the extraction technique on the antioxidant and antimicrobial activities separately [11,12].

The microwave-assisted extraction (MAE) involves the formation of high-energy electromagnetic waves with a frequency, oscillation period, and wavelength ranging from $300 \mathrm{MHz}-30 \mathrm{GHz}$, $3 \times 10^{-9} \mathrm{~s}-33 \times 10^{-12} \mathrm{~s}$, and $1-10 \mathrm{~mm}$, respectively. These waves have the ability to change the molecular rotation and ionic mobility of the medium without altering the sample. This rotation generates the adsorption and dissipation of energy in the medium, causing a generalized heating, forcing the rapid migration of all the active compounds from the solid-phase to the solvent-phase [7,13-17]

For this reason, the goal of this study was to define the optimal microwave-assisted extraction (MAE) conditions to render the bioactive compounds of annatto seeds without affecting their antioxidant and antimicrobial activities. The solvent concentration, $\mathrm{pH}$, treatment time and solvent-to-seed ratio were taken as independent variables employing a surface response experimental design.

\section{Materials and Methods}

\subsection{Materials}

Sodium carbonate (lot a0594092339), anhydrous sodium acetate (lot 882032), absolute ethanol (lot k4958171742), potassium persulphate (lot k40707991048), methanol (lot 1823009611), acetic acid glacial (lot k47109963539), acetone (lot k43912814243), sodium hydroxide (lot b0895598319), concentrated hydrochloric acid (lot k41017317016), Folin-Ciocalteu phenol reagent (lot hc43368401), Mueller-Hinton broth (lot b1223098542), tetrahydrofuran (lot dg643), and 
2,4,6-tri-(2-pyridyl)-1,3,5-triazine (lot 158155738107) were obtained from Merck (Darmstadt, Germany). Dimethyl sulfoxide (lot 190260) was obtained from PanReac AppliChem (Barcelona, Spain). 2,2'-Azino-bis(3-ethylbenzothiazoline-6-sulfonic acid), 2, 2-diphenyl-1-picrylhydrazil (067k lot 1154), and diammonium salt (lot slbp9592v) were obtained from Sigma-Aldrich (St. Louis, MO, USA). ( \pm )-6-Hydroxy-2,5,7,8-tetramethylchromane-2-carboxylic acid (Trolox) (97\% lot stbb6668) was obtained from Aldrich Chem (St. Louis, MO, USA). Ferric chloride. $6 \mathrm{H}_{2} \mathrm{O}$ (lot 9n005099n) was obtained from Carlo Erba (Barcelona, Spain). 3-(4,5-Dimethylthiazol-2-yl)-2,5-diphenyltetrazolium bromide (MTT) (lot p31b064) was obtained from Alfa Aesar (Haverhill, MA, USA). Annatto seeds were purchased from a farmers market of Medellín city (Colombia), which were sun-dried until reaching a moisture content of $10.58 \pm 0.98 \%$.

\subsection{Experimental Design}

The MAE conditions were optimized using a Box-Behnken experimental design (BBD), employing the Design Expert Software ${ }^{\circledR}$ Version 8.0.6 (Stat-Ease, MN, USA). The dependent variables for the two extraction methods are described in Table 1. From these conditions, 30 experimental runs were established and presented in a randomized pattern. The amount of total polyphenols determined by the Folin-Ciocalteu method, and the bixin (Bix) content were taken as independent variables [18].

Table 1. Factor levels of the independent variables according to the Box-Behnken experimental design (BBD).

\begin{tabular}{ccccc}
\hline \multirow{2}{*}{ Independent Variables } & \multirow{2}{*}{ Symbol } & \multicolumn{3}{c}{ Coded Levels } \\
\cline { 3 - 5 } & & $\mathbf{- 1}$ & $\mathbf{0}$ & $\mathbf{+ 1}$ \\
\hline Treatment time (min) & $\mathrm{X}_{1}$ & 0 & 2.5 & 5 \\
$\mathrm{pH}$ & $\mathrm{X}_{2}$ & 4 & 7.5 & 11 \\
Solvent concentration (ethanol) $(\%)$ & $\mathrm{X}_{3}$ & 50 & 73 & 96 \\
Solvent-to-seed ratio $\left(\mathrm{X}_{4}: 1\right)$ & $\mathrm{X}_{4}$ & 2 & 6 & 10 \\
\hline
\end{tabular}

The solvent $\mathrm{pH}$ at the concentrations determined by the BBD was adjusted with $0.1 \mathrm{M}$ sodium hydroxide and acetic acid solutions. The microwave unit was operated at a frequency of $2450 \mathrm{MHz}$ and power of 700 W (LG Ms-147xc, Seoul, South Korea), submitting the sample to 30-s cycles until reaching the desirable total time (Figure 1). In order to optimize the extraction conditions and investigate the effect of the independent variables the method of multiple regression of least squares was used. The coefficient of determination $\left(\mathrm{r}^{2}\right)$ and the adjusted coefficient of determination ( $\mathrm{r}^{2}$-adj model) were used as fitting parameters of the regression models. The experimental data were adjusted to the following polynomial equation:

$$
\begin{gathered}
Y=\beta_{0}+\beta_{1} X_{1}+\beta_{2} X_{2}+\beta_{3} X_{3}+\beta_{4} X_{4}+\beta_{11} X_{1} X_{1}+\beta_{22} X_{2} X_{2}+\beta_{33} X_{3} X_{3}+\beta_{44} X_{4} X_{4}+\beta_{12} X_{1} X_{2}+ \\
\beta_{13} X_{1} X_{3}+\beta_{14} X_{1} X_{4}+\beta_{23} X_{2} X_{3}+\beta_{24} X_{2} X_{4}+\beta_{34} X_{3} X_{4} .
\end{gathered}
$$

where, $Y$ represents the predicted response, $\beta_{0}$, is the intercept of the model, $\beta_{1}, \beta_{2}, \beta_{3}, \beta_{4}, \beta_{11}$, $\beta_{22}, \beta_{33}, \beta_{44}$ and $\beta_{12}, \beta_{13}, \beta_{14}, \beta_{23}, \beta_{24}$ and, $\beta_{34}$ are linear and interaction coefficients, respectively, and $X_{1}, X_{2}, X_{3}$, and, $X_{4}$ are independent variables. The analysis of variance (ANOVA) was used to investigate the statistical significance of the independent variables from the models obtained (with a confidence level of 95\%). The optimization of the extraction process was achieved by maximizing the extraction of polyphenol compounds and bixin having the same weight (weight of 1) and minimizing the solvent-to-seed ratio. The accuracy of the optimal conditions was determined with the desirability values of the dependent factors. The calculation of the relative and absolute errors was accomplished between the responses predicted by the model versus the ones obtained experimentally under optimal conditions. 


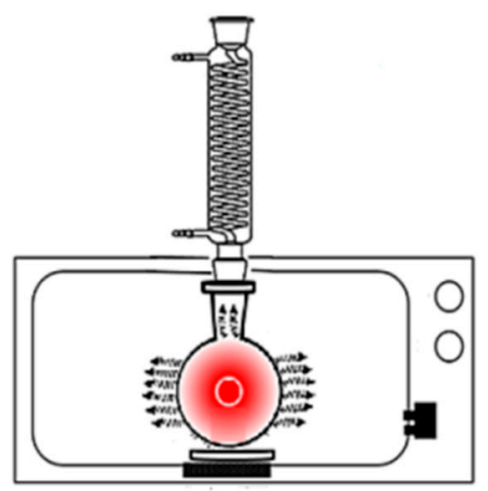

Figure 1. Schematics for microwave-assisted extraction (MAE) from annatto seeds.

\subsection{Characterization of Optimal Annatto Seed Extracts}

The optimal extract obtained by the MAE was compared with the one obtained by leaching. The latter was obtained with ethanol using at optimum concentration, $\mathrm{pH}$, and seeds-to-solvent ratio for the MAE, with a continuous agitation for $48 \mathrm{~h}$. The results are presented as means and standard deviation (SD). The analysis was performed using the Statgraphics ${ }^{\circledR}$ Centurion XVI software (Madrid, Spain).

\subsubsection{Total Polyphenol Concentration}

The total polyphenol concentration in the annatto seed extract was determined using the Folin-Ciocalteau method [19]. Briefly, $20 \mu \mathrm{L}$ of sample were diluted in $1.58 \mu \mathrm{L}$ of distilled water. Then, $100 \mu \mathrm{L}$ of Folin-Ciocalteau reagent and $300 \mu \mathrm{L}$ of $20 \%$ sodium carbonate were added and mixed. The absorbance of the colored complex generated was read after $1 \mathrm{~h}$ of storage under darkness. The maximum absorbance was read at $725 \mathrm{~nm}$ in a UV/VIS spectrophotometer (UV-1700, Shimadzu ${ }^{\circledR}$, Kyoto, Japan). The experiments were performed in triplicate and the results are expressed as mg of gallic acid (GA) per grams of seeds (mg GA/g seed).

\subsubsection{Quantification of Bixin}

Here, $100 \mu \mathrm{L}$ of sample were added to $2 \mathrm{~mL}$ of tetrahydrofuran and diluted to $10 \mathrm{~mL}$ with acetone to obtain an absorbance of less than 0.15 at $487 \mathrm{~nm}$. The concentration of bixin in the sample was determined from a calibration curve built in a spectrophotometer (UV-1700, Shimadzu ${ }^{\circledR}$, Kyoto Japan) using the following equation (Equation (2)) [20]:

$$
\operatorname{Bixin}(\%)=\frac{\mathrm{A} \times 100 \times \mathrm{V}}{A_{1 \mathrm{~cm}}^{1 \%} \times 100}
$$

where

$A_{1 \mathrm{~cm}}^{1 \%}=3090(1 \mathrm{~g} / 100 \mathrm{~mL})^{-1} \times 1 \mathrm{~cm}^{-1}$ (specific absorptivity coefficient of bixin in acetone) [20];

$\mathrm{A}=$ Absorbance value of the sample; and

$\mathrm{V}=$ Dilution volume $(\mathrm{mL})$ of the sample.

\subsubsection{Antioxidant Activity $\left(\mathrm{ABTS}^{+}\right.$Method)}

The ABTS assay was performed following the method described by Contreras et al. 2011 [21]. Briefly, $100 \mu \mathrm{L}$ of sample (diluted appropriately with water) were mixed with $1 \mathrm{~mL}$ of $\mathrm{ABTS}^{+}$solution. The degraded color was read after $30 \mathrm{~min}$ at $730 \mathrm{~nm}$ using a spectrophotometer (UV-1700, Shimadzu ${ }^{\circledR}$, Kyoto, Japan). A Trolox calibration curve was conducted for quantification purposes and the results are expressed as Trolox equivalents (TE) or $\mu \mathrm{mol} \mathrm{TE} / \mathrm{L}$. 


\subsubsection{Ferric Reducing Antioxidant Power (FRAP)}

The FRAP was measured as previously described by Benzie and Strain (1996) with modifications [22]. Briefly, $90 \mu \mathrm{L}$ of deionized water were mixed with $30 \mu \mathrm{L}$ of sample (diluted appropriately with water) and added to $900 \mu \mathrm{L}$ of the FRAP reagent (pre-warmed at $37^{\circ} \mathrm{C}$ ). The sample was incubated for $30 \mathrm{~min}$ at $37^{\circ} \mathrm{C}$. Subsequently, the sample absorbance at $593 \mathrm{~nm}$ was measured using a spectrophotometer (UV-1700, Shimadzu ${ }^{\circledR}$, Kyoto, Japan). A Trolox ${ }^{\circledR}$ calibration curve was employed for quantification purposes and the results are expressed as $\mu \mathrm{mol} \mathrm{TE} / \mathrm{L}$.

\subsubsection{Antioxidant Activity (DPPH Method)}

The DPPH assay was performed as previously described [23]. Briefly, $2 \mathrm{~mL}$ of $0.5 \mathrm{mM} \mathrm{DPPH}$ reagent was mixed with $2 \mathrm{~mL}$ of methanol and $0.2 \mathrm{~mL}$ of sample (diluted appropriately with water). The absorbance peak at $517 \mathrm{~nm}$ was recorded after $30 \mathrm{~min}$ of incubation under darkness (UV-1700, Shimadzu ${ }^{\circledR}$, Kyoto, Japan). A Trolox ${ }^{\circledR}$ calibration curve was done for quantification purposes and the results are expressed as $\mu \mathrm{mol} \mathrm{TE} / \mathrm{L}$.

\subsubsection{Antimicrobial Activity of Annatto Seed Extracts}

The antibacterial activity was determined employing the colorimetric microdilution method with broth incubated with Bacillus cereus (ATCC 11778) and Staphylococcus aureus (ATCC 6538). Bacterial strains were incubated for $24 \mathrm{~h}$ at $37^{\circ} \mathrm{C}$ in a Mueller-Hinton broth and adjusted to a final density of $10^{6} \mathrm{CFU} / \mathrm{mL}$ before inoculation. Samples were dissolved in dimethylsulfoxide (DMSO) to reach a final concentration of $4.096 \mathrm{mg} / \mathrm{L}$. Double serial dilutions were made at a concentration ranging from 4 to $4096 \mathrm{mg} / \mathrm{L}$. Then, 96-well microplates were prepared by adding $20 \mu \mathrm{L}$ of sample on the respective dilution medium followed by addition of $220 \mu \mathrm{L}$ of Mueller-Hinton broth. The last row containing only $220 \mu \mathrm{L}$ of Mueller-Hinton broth and $10 \mu \mathrm{L}$ of inoculum was used as a negative control. The final volume in each well was $250 \mu \mathrm{L}$. Once the samples were homogenized, they were incubated for $5 \mathrm{~h}$ at $37^{\circ} \mathrm{C}$. After incubation, $25 \mu \mathrm{L}$ of 3-(4,5-dimethylthiazol-2-yl)-2,5-diphenyl-tetrazolium bromide (MTT) (Alfa Aesar, Germany), dissolved in DMSO $(800 \mathrm{mg} / \mathrm{L})$ were added to each well and incubated for $1 \mathrm{~h}$ to allow viable microorganisms to metabolize the yellow MTT dye in formazan. The minimum inhibitory concentration (MIC) was considered as the concentration of the first well that did not show any color change (from yellow to purple). The procedure was repeated three times for each microorganism and $\mathrm{pH}(4,7$, and 11) [1].

\subsection{Statistical Analysis}

The results are presented as means and standard deviation (SD), according to the normality of the data. The analysis was performed using the Statgraphics ${ }^{\circledR}$ centurion XVI software (Madrid, Spain).

\section{Results}

\subsection{Experimental Design}

The experimental matrix was composed of 30 experimental runs. Experiments were performed in triplicate and the tabulated results from each experimental run are described in Table 2. The maximum values achieved in the extraction process were $4.36 \pm 0.04 \mathrm{mg} \mathrm{GA} / \mathrm{g}$ seed and $0.51 \pm 0.01 \%$ of bixin. These values were obtained at $2.5 \mathrm{~min}$ time for $\mathrm{MAE}, \mathrm{pH}$ of 11 , and a solvent-to-seed ratio of $6: 1$. The only variation between the extractions corresponded to the solvent concentration used at a $50 \%$ for the maximum extraction of polyphenol compounds and $96 \%$ for the maximum extraction of bixin.

ANOVA was used to evaluate the significance of the quadratic polynomial models. For each term in the models, a large $F$-value and a small $p$-value would imply a more significant effect on the respective response variable [24]. The ANOVA (Table 3) shows how factors such as treatment time, 
solvent concentration and the solvent-to-seed ratio had a statistically significant effect $(p<0.05)$ for the MAE.

Table 2. Experimental matrix and results obtained from the MAE.

\begin{tabular}{|c|c|c|c|c|c|c|}
\hline \multirow[b]{2}{*}{$\begin{array}{c}\text { Treatment } \\
\text { Number }\end{array}$} & \multirow[b]{2}{*}{$\begin{array}{l}\text { MAE } \\
\text { (min) }\end{array}$} & \multirow[b]{2}{*}{$\mathrm{pH}$} & \multirow{2}{*}{$\begin{array}{c}\text { Solvent } \\
\text { Concentration } \\
\text { (Ethanol) (\%) }\end{array}$} & \multirow[b]{2}{*}{$\begin{array}{c}\text { Solvent-to-Seed } \\
\text { Ratio }\left(\mathrm{X}_{4}: 1\right)\end{array}$} & \multicolumn{2}{|c|}{ MAE } \\
\hline & & & & & $\begin{array}{c}\text { Polyphenols } \\
\text { (mg GA/g Seed) } \\
n=3\end{array}$ & $\begin{array}{c}\text { Bixin (\%) } \\
n=3\end{array}$ \\
\hline 1 & 2.5 & 7.5 & 73.0 & 10.0 & $2.83 \pm 0.04$ & $0.13 \pm 0.00$ \\
\hline 2 & 2.5 & 4.0 & 50.0 & 6.0 & $1.53 \pm 0.22$ & $0.03 \pm 0.00$ \\
\hline 3 & 2.5 & 7.5 & 50.0 & 10.0 & $2.85 \pm 0.19$ & $0.05 \pm 0.00$ \\
\hline 4 & 5.0 & 4.0 & 96.0 & 6.0 & $1.96 \pm 0.06$ & $0.33 \pm 0.04$ \\
\hline 5 & 2.5 & 7.5 & 73.0 & 6.0 & $1.96 \pm 0.15$ & $0.05 \pm 0.01$ \\
\hline 6 & 5.0 & 11.0 & 73.0 & 6.0 & $2.01 \pm 0.08$ & $0.13 \pm 0.02$ \\
\hline 7 & 5.0 & 11.0 & 73.0 & 6.0 & $1.35 \pm 0.05$ & $0.32 \pm 0.01$ \\
\hline 8 & 2.5 & 11.0 & 96.0 & 6.0 & $3.94 \pm 0.00$ & $0.51 \pm 0.01$ \\
\hline 9 & 5.0 & 7.5 & 50.0 & 6.0 & $3.79 \pm 0.07$ & $0.04 \pm 0.01$ \\
\hline 10 & 2.5 & 7.5 & 50.0 & 2.0 & $0.53 \pm 0.08$ & $0.27 \pm 0.03$ \\
\hline 11 & 2.5 & 4.0 & 73.0 & 6.0 & $4.16 \pm 0.24$ & $0.19 \pm 0.00$ \\
\hline 12 & 2.5 & 4.0 & 73.0 & 2.0 & $0.83 \pm 0.06$ & $0.12 \pm 0.01$ \\
\hline 13 & 2.5 & 7.5 & 73.0 & 6.0 & $1.89 \pm 0.14$ & $0.05 \pm 0.01$ \\
\hline 14 & 2.5 & 7.5 & 96.0 & 6.0 & $1.72 \pm 0.15$ & $0.19 \pm 0.00$ \\
\hline 15 & 2.5 & 11.0 & 73.0 & 10.0 & $3.25 \pm 0.57$ & $0.04 \pm 0.01$ \\
\hline 16 & 2.5 & 11.0 & 50.0 & 6.0 & $4.36 \pm 0.04$ & $0.03 \pm 0.00$ \\
\hline 17 & 2.5 & 7.5 & 96.0 & 6.0 & $2.43 \pm 0.01$ & $0.58 \pm 0.00$ \\
\hline 18 & 2.5 & 7.5 & 96.0 & 2.0 & $0.66 \pm 0.01$ & $0.38 \pm 0.03$ \\
\hline 19 & 0.0 & 7.5 & 73.0 & 6.0 & $1.96 \pm 0.08$ & $0.06 \pm 0.01$ \\
\hline 20 & 5.0 & 7.5 & 96.0 & 10.0 & $2.10 \pm 0.01$ & $0.13 \pm 0.00$ \\
\hline 21 & 2.5 & 7.5 & 73.0 & 2.0 & $0.70 \pm 0.01$ & $0.07 \pm 0.02$ \\
\hline 22 & 0.0 & 7.5 & 73.0 & 6.0 & $1.90 \pm 0.23$ & $0.04 \pm 0.00$ \\
\hline 23 & 2.5 & 11.0 & 73.0 & 2.0 & $0.68 \pm 0.03$ & $0.17 \pm 0.01$ \\
\hline 24 & 0.0 & 7.5 & 73.0 & 10.0 & $2.15 \pm 0.16$ & $0.10 \pm 0.01$ \\
\hline 25 & 2.5 & 4.0 & 73.0 & 6.0 & $2.28 \pm 0.01$ & $0.12 \pm 0.03$ \\
\hline 26 & 0.0 & 7.5 & 73.0 & 6.0 & $2.02 \pm 0.03$ & $0.08 \pm 0.00$ \\
\hline 27 & 0.0 & 7.5 & 50.0 & 6.0 & $3.90 \pm 0.30$ & $0.08 \pm 0.00$ \\
\hline 28 & 2.5 & 7.5 & 73.0 & 2.0 & $1.57 \pm 0.30$ & $0.25 \pm 0.01$ \\
\hline 29 & 0.0 & 4.0 & 73.0 & 10.0 & $1.96 \pm 0.15$ & $0.33 \pm 0.01$ \\
\hline 30 & 5.0 & 7.5 & 73.0 & 6.0 & $1.91 \pm 0.18$ & $0.06 \pm 0.02$ \\
\hline
\end{tabular}

Values are expressed as mean \pm standard deviation $(n=3)$. MAE: microwave-assisted extraction, GA: gallic acid.

Table 3. ANOVA for the response variables in the MAE.

\begin{tabular}{ccc}
\hline & $\begin{array}{c}\text { Polyphenols } \\
\text { Variable }\end{array}$ & Bixin (\%) \\
\cline { 2 - 3 } & $p$-Value & $p$-Value \\
\hline Model & $<0.0001$ & $<0.0001$ \\
$\mathrm{X}_{1}$, treatment time (min) & $<0.0001$ & $<0.0001$ \\
$\mathrm{X}_{2}, \mathrm{pH}$ & 0.532 & 0.112 \\
$\mathrm{X}_{3}$, solvent concentration $(\%)$ & $<0.0001$ & $<0.0001$ \\
$\mathrm{X}_{4}$, solvent-to-seed ratio $(\mathrm{X} 4: 1)$ & $<0.0001$ & 0.677 \\
$\mathrm{X}_{2} \mathrm{X}_{3}$ & 0.001 & $>0.050$ \\
$\mathrm{X}_{2} \mathrm{X}_{4}$ & 0.044 & 0.001 \\
$\mathrm{X}_{3} \mathrm{X}_{4}$ & $>0.050$ & 0.004 \\
$\mathrm{X}_{2} \mathrm{X}_{2}$ & $>0.050$ & $<0.0001$ \\
$\mathrm{X}_{4} \mathrm{X}_{4}$ & $<0.0001$ & $>0.050$ \\
$\mathrm{X}_{1} \mathrm{X}_{1}$ & $<0.0001$ & $<0.0001$ \\
Lack of fit & 0.0405 & 0.137 \\
$\mathrm{r}^{2}$ & 0.931 & 0.914 \\
$\mathrm{r}^{2}$-adj & 0.901 & 0.875 \\
\hline
\end{tabular}


The response surface plots obtained from the polynomial equations are shown in Figure 2. All the models were subjected to an optimization process and the polynomial equations for the response variables are described as follows:

$$
\begin{aligned}
& \text { Ln }(\text { Polyphenols })=0.70+0.03 \times X_{2}-0.26 \times X_{3}+0.53 \times X_{4}+0.26 \times X_{1}-0.42 \times X_{2} X_{3}+ \\
& 0.18 \times \mathrm{X}_{2} \mathrm{X}_{4}-0.41 \times \mathrm{X}_{4}^{2}+0.29 \times \mathrm{X}_{1}^{2} \\
& \operatorname{Ln}(\text { Bixin })=-0.59-1.12 \times X_{2}-0.04 \times X_{3}+0.76 \times X_{4}-0.15 \times X_{1}+0.04 \times X_{2} X_{4} \\
& -0.01 \times \mathrm{X}_{3} \mathrm{X}_{4}+0.06 \times \mathrm{X}_{2}{ }^{2}+0.01 \times \mathrm{X}_{4}{ }^{2}+0.10 \times \mathrm{X}_{1}^{2}
\end{aligned}
$$

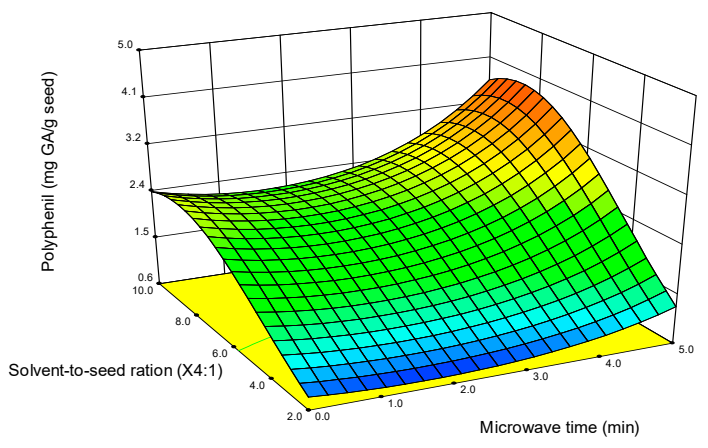

(a)

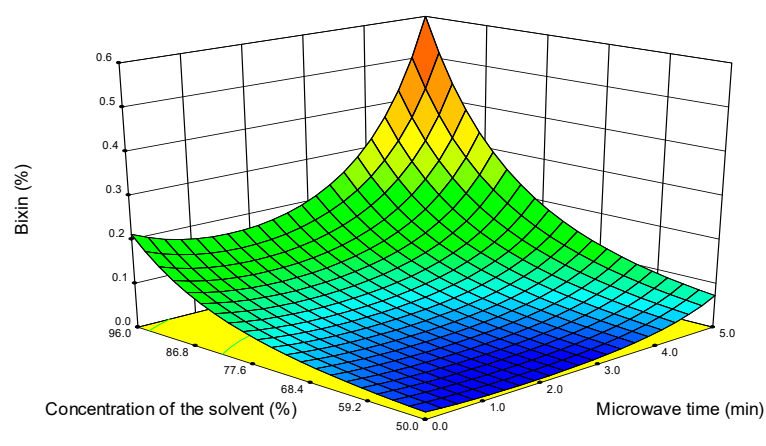

(b)

Figure 2. Response surface plots of solvent concentration (ethanol) and treatment conditions for: (a) polyphenol compounds and (b) bixin.

The response surfaces plots depict how the application of microwaves accelerates the process of extraction of the bioactive compounds. When a longer treatment time was applied the yield of bioactive compounds was larger. Once both dependent variables were optimized (polyphenol compounds and bixin), the estimated conditions for the MAE along with their relative error were as listed in Table 4 . The absolute bias for the MAE process was high, and thus the experimental results obtained were greater than those predicted by the models.

Table 4. Predicted local maximum for the optimization of the MAE applying a Box-Behnken experimental design.

\begin{tabular}{cccccc}
\hline $\mathbf{p H}$ & $\begin{array}{c}\text { Solvent } \\
\text { (Ethanol) (\%) }\end{array}$ & $\begin{array}{c}\text { Solvent-to-Seed } \\
\text { Ratio }\left(\mathbf{X}_{\mathbf{4}}: \mathbf{1}\right)\end{array}$ & $\begin{array}{c}\text { Treatment } \\
\text { Time (min) }\end{array}$ & $\begin{array}{c}\text { Polyphenol } \\
\text { (mg GA/g Seed) }\end{array}$ & Bixin (\%) \\
\hline 7.00 & 96 & 5.95 & 5.00 & 2.69 & 0.58 \\
& & Experimental result & & $3.08 \pm 0.01$ & $0.58 \pm 0.02$ \\
& & Relative error & -0.39 & 0.00 \\
& & Absolute error (\%) & 14.41 & 0.55 \\
\hline
\end{tabular}

Values are expressed as mean \pm standard deviation $(n=3)$.

The absolute error compares the results predicted by the optimized model to the experimental ones obtained under optimal conditions. It indicates that the bixin extraction models using MAE are more precise than those obtained for the extraction of polyphenol compounds.

\subsection{Effect of the MAE on the Antimicrobial and Antioxidant Activities of the Extract}

The antioxidant and antimicrobial properties of the extracts obtained at the optimal operation conditions of the MAE were compared to those obtained by leaching. Table 5 shows larger antimicrobial and antioxidant activities for the MAE than those obtained by leaching. This is explained by the higher content of polyphenol and bixin compounds present in MAE. 
Table 5. Comparison of the antioxidant and antimicrobial activities of annatto extracts obtained by MAE and leaching.

\begin{tabular}{|c|c|c|c|}
\hline \multicolumn{2}{|c|}{ Extract } & \multirow{2}{*}{$\frac{\text { MAE }}{0.576^{b} \pm 0.015}$} & \multirow{2}{*}{$\begin{array}{c}\text { Leaching } \\
0.165^{\mathrm{a}} \pm 0.002\end{array}$} \\
\hline Bixin & $(\%)$ & & \\
\hline Polyphenols & (mg GA/g seed) & $3.078^{b} \pm 0.012$ & $0.343^{\mathrm{a}} \pm 0.003$ \\
\hline ABTS & ( $\mu \mathrm{M}$ Trolox/L extract) & $577^{\mathrm{b}} \pm 5$ & $174^{\mathrm{a}} \pm 8$ \\
\hline FRAP & ( $\mu \mathrm{M}$ Trolox/L extract) & $316^{\mathrm{b}} \pm 10$ & $127^{\mathrm{a}} \pm 2$ \\
\hline \multirow[t]{2}{*}{ DPPH } & ( $\mu \mathrm{M}$ Trolox/L extract) & $1043^{b} \pm 50$ & $811^{a} \pm 5$ \\
\hline & $\mathrm{pH} 11(\mathrm{mg} / \mathrm{L})$ & $16^{\mathrm{a}}$ & $128^{\mathrm{b}}$ \\
\hline \multirow[t]{3}{*}{ Bacillus cereus } & $\mathrm{pH} 7$ (mg/L) & $16^{\mathrm{a}}$ & $128^{b}$ \\
\hline & $\mathrm{pH} 4(\mathrm{mg} / \mathrm{L})$ & $16^{\mathrm{a}}$ & $128^{b}$ \\
\hline & $\mathrm{pH} 11(\mathrm{mg} / \mathrm{L})$ & $8^{a}$ & $32^{b}$ \\
\hline \multirow[t]{2}{*}{ Staphylococcus aureus } & $\mathrm{pH} 7$ (mg/L) & $8^{\mathrm{a}}$ & $32^{b}$ \\
\hline & $\mathrm{pH} 4(\mathrm{mg} / \mathrm{L})$ & $8^{a}$ & $32^{b}$ \\
\hline
\end{tabular}

Different superscript letters within row indicate significant differences $(p<0.05)$ according to LSD-Fisher; values are expressed as mean \pm standard deviation $(n=3)$. ABTS: 2,2'-azino-bis(3-ethylbenzothiazoline-6-sulphonic acid), FRAP: Ferric Reducing Antioxidant Power, and DPPH: 2,2-Diphenyl-1-picrylhydrazyl

\section{Discussion}

The evaluation of the variables studied and optimized responses; microwave treatment time, $\mathrm{pH}$, solvent concentration $(\%)$, and solvent-to-seed ratio $\left(X_{4}: 1\right)$, showed a significant effect $(p<0.05)$ on the extraction of the polyphenol compounds and bixin from annatto seeds. Table 2 shows the variability of the results obtained in each experimental unit, with results varying from 0.53 to $4.36 \mathrm{mg} \mathrm{GA} / \mathrm{g}$ seeds for polyphenol compounds and from 0.03 to $0.58 \%$ for bixin. This variability is confirmed by the ANOVA (Table 3), showing that all the independent variables studied had a greater influence in the extraction process for both metabolites.

The influence of these conditions on the extraction process is mainly due to (1) the increase in the mass transfer capacity and/or the extraction power of the system, (2) the affinity of the bioactive compounds towards the solvent, and (3) the effect of the heat generated on the micro-domains of the system [25]. By increasing the solvent-to-seed ratio, the saturation point of the system is favored increasing the mobility of the seeds in the agitated system, generating a greater mass transfer of the bioactive compounds to solvent [25]. The amount of solvent in the system not only affected the extraction capability of the system, but also had a statistically significant interaction effect $\left(\mathrm{X}_{3} \mathrm{X}_{4}\right)$ (Table 3), improving the affinity of the compounds towards the extractive solvent resulting in an enhanced mass transfer process. Polyphenol compounds present in annatto extract (i.e., apigenin, hypolaetin, and the caffeic acid derivative) possess a larger polarity as compared to bixin, which is a highly conjugated long chain molecule, also known for having a very low solubility. Therefore, increasing the concentration of ethanol favors the release of bixin by having a higher solvent content to form hydrogen bonds, and in the case of polyphenol compounds the extraction is favored by its polarity $[3,26,27]$.

On the other hand, the effect of $\mathrm{pH}$ was not significant in its linear term for the extraction of the polyphenol compounds and bixin. This result is opposite to that of Rubio-Senent and collaborators, who demonstrated that the activity and solubility of polyphenol compounds and bixin were affected by $\mathrm{pH}$. Further, bixin, is a carotenoid having a highly conjugated structure and a carboxyl end-group. As a result, its solubility at neutral and alkaline $\mathrm{pH}$ was limited. Conversely, the polyphenol compounds possess an aromatic ring structure which is attached to hydroxyl groups or other planar rings. These molecules are slightly acidic and their solubility and activity are maximized at neutral and slightly acidic $\mathrm{pH}$ [28]. The insignificance of $\mathrm{pH}$ in the system can be attributed to the powerful effect of other independent variables studied which overshadowed its effect.

The microwave treatment time was significant $(p<0.05)$ since it increased the extraction power for the polyphenol compounds and bixin. However, polyphenol compounds were more sensitive to 
this extraction process than bixin (Figure 2a) since once the maximum point of extraction was reached, the content of polyphenols steadily decreased. This is explained by the heat generated during the microwave treatment. Thus, the longer the treatment, the larger the temperature reached in the system, causing solvent volatilization along with a partial degradation of the polyphenol compounds. Some authors have reported that the bioactivity of these secondary metabolites are affected by the extraction mechanism and heat treatments [7,29]. On the other hand, the optimal extraction conditions were found when a $\mathrm{pH}$ of 7 , solvent concentration of $96 \%$, solvent-to-seed ratio of $6: 1$, and a microwave time of $5 \mathrm{~min}$ were in place. These conditions rendered the largest yield of polyphenol and bixin compounds. It is then worthy to mention that the antioxidant and antimicrobial activities of the optimized extract were probably due to its largest content of polyphenol and bixin compounds, which in turn were responsible for their antioxidant and antimicrobial activities. These results coincide with those reported by Vasu et al. in 2010, which extracted only bixin from B. orellana seeds by applying microwaves for a time of $18 \mathrm{~min}$ as compared to a leaching extraction for $80 \mathrm{~min}$. As a result, the bixin extraction raised from $8.2 \%$ to $16.3 \%$. They also claimed that MAE is an alternative green technology and superior to conventional extraction for the extraction of bixin [12].

On the one hand, the antioxidant activity increased for the extract obtained by MAE, with a 5-and 10-fold increase of bixin and polyphenol compounds, respectively, as compared to the extract obtained by leaching. Moreover, the extract obtained by MAE presented antimicrobial activity against $B$. cereus and $S$. aureus. There were statistically significant differences $(p<0.05)$ for both activities between treatments, where MAE presented greater in vitro activities thanks to the high contents of polyphenols and antioxidant compounds. However, a direct proportional association was not appreciated between the increase of the bioactive compounds and the increments of the antimicrobial and antioxidant activities. Thus, the antioxidant activity was the most affected variable by the extraction method. The results of the antimicrobial and antioxidant activities of the lyophilized extract are comparable with those reported by some authors [1,12,30].

\section{Conclusions}

The MAE technique increased the yield of polyphenol compounds and bixin extracted from the annatto seeds, reducing energy consumption and increasing the antioxidant capability of extracts obtained. Despite the fact that the active compounds had a larger yield as compared to leaching, the antimicrobial activity did not present significant differences.

Author Contributions: Conceptualization, J.Q.Q., G.C.G., and J.R.C.; Investigation, J.Q.Q., A.C.T., L.M.R., and M.S.G.; writing-Original draft preparation, J.Q.Q., A.C.T., L.M.R., and M.S.G.; Writing-Review and editing, G.C.G. and J.R.C.; Supervision, G.C.G., and J.R.C.; funding acquisition, J.Q.Q., G.C.G., and J.R.C.

Funding: This work was sponsored by Colciencias through the grant 727 of 2015 for the formation of Colombian PhDs and 715 for research and development projects in engineering-2015. The authors also thank the sustainability strategy of CODI 2018-2019.

Conflicts of Interest: The authors declare no conflict of interest.

\section{References}

1. Viuda, M.; Ciro, G.L.; Ruiz, Y.; Zapata, J.E.; Sendra, E.; Pérez-Álvarez, J.A.; Fernández-López, J. In vitro Antioxidant and Antibacterial Activities of Extracts from Annatto (Bixa orellana L.) Leaves and Seeds. J. Food Saf. 2012, 32, 399-406. [CrossRef]

2. Zhang, H.; Xue, L.; Li, B.; Tian, H.; Zhang, Z.; Tao, S. Therapeutic potential of bixin in PM2.5 particles-induced lung injury in an Nrf2-dependent manner. Free Radic. Biol. Med. 2018, 126, 166-176. [CrossRef] [PubMed]

3. Campos, R.; Yamashita, F.; Cesar, F.; Zerlotti, A. Simultaneous extraction and analysis by high performance liquid chromatography coupled to diode array and mass spectrometric detectors of bixin and phenolic compounds from annatto seeds. J. Chromatogr. A 2011, 1218, 57-63. [CrossRef]

4. Butnariu, M. Methods of Analysis (Extraction, Separation, Identification and Quantification) of Carotenoids from Natural Products. J. Ecosyst. Ecography 2016, 6, 1-19. [CrossRef] 
5. Shahid-ul-Islam, L.J.; Mohammad, F. Phytochemistry, biological activities and potential of annatto in natural colorant production for industrial applications-A review. J. Adv. Res. 2016, 7, 499-514. [CrossRef] [PubMed]

6. Zhang, B.; Tomita, Y.; Qiu, Y.; He, J.; Morii, E.; Noguchi, S.; Aozasa, K. E74-like factor 2 regulates valosin-containing protein expression. Biochem. Biophys. Res. Commun. 2007, 356, 536-541. [CrossRef] [PubMed]

7. Yolmeh, M.; Habibi Najafi, M.B.; Farhoosh, R. Optimisation of ultrasound-assisted extraction of natural pigment from annatto seeds by response surface methodology (RSM). Food Chem. 2014, 155, 319-324. [CrossRef] [PubMed]

8. Lianfu, Z.; Zelong, L. Optimization and comparison of ultrasound/microwave assisted extraction (UMAE) and ultrasonic assisted extraction (UAE) of lycopene from tomatoes. Ultrason. Sonochem. 2008, 15, 731-737. [CrossRef]

9. Alcázar-Alay, S.C.; Osorio-Tobón, J.F.; Forster-Carneiro, T.; Meireles, M.A.A. Obtaining bixin from semi-defatted annatto seeds by a mechanical method and solvent extraction: Process integration and economic evaluation. Food Res. Int. 2017, 99, 393-402. [CrossRef]

10. Taham, T.; Silva, D.O.; Barrozo, M.A.S. Improvement of bixin extraction from annatto seeds using a screen-topped spouted bed. Sep. Purif. Technol. 2016, 158, 313-321. [CrossRef]

11. Rodrigues, L.M.; Alcázar-Alay, S.C.; Petenate, A.J.; Meireles, M.A.A. Bixin extraction from defatted annatto seeds. C. R. Chim. 2014, 17, 268-283. [CrossRef]

12. Soumya, V.; Venkatesh, P.; Kothandam, H.P. Microwave facilitated extraction of bixin from Bixa orellana and it's in-vitro antioxidant activity. Der Pharm. Lett. 2010, 2, 479-485.

13. Zou, T.B.; Jia, Q.; Li, H.W.; Wang, C.X.; Wu, H.F. Response surface methodology for ultrasound-assisted extraction of astaxanthin from Haematococcus pluvialis. Mar. Drugs 2013, 11, 1644-1655. [CrossRef] [PubMed]

14. Teng, H.; Jo, I.H.; Choi, Y.H. Optimization of ultrasonic-assisted extraction of phenolic compounds from chinese quince (Chaenomeles sinensis) by response surface methodology. J. Appl. Biol. Chem. 2010, 53, 618-625. [CrossRef]

15. Da Porto, C.; Porretto, E.; Decorti, D. Comparison of ultrasound-assisted extraction with conventional extraction methods of oil and polyphenols from grape (Vitis vinifera L.) seeds. Ultrason. Sonochem. 2013, 20, 1076-1080. [CrossRef] [PubMed]

16. Ahmed, M.; Akter, M.S.; Eun, J.B. Optimization conditions for anthocyanin and phenolic content extraction form purple sweet potato using response surface methodology. Int. J. Food Sci. Nutr. 2011, 62, 91-96. [CrossRef] [PubMed]

17. Ghafoor, K.; Choi, Y.H.; Jeon, J.Y.; Jo, I.H. Optimization of ultrasound-assisted extraction of phenolic compounds, antioxidants, and anthocyanins from grape (Vitis vinifera) seeds. J. Agric. Food Chem. 2009, 57, 4988-4994. [CrossRef]

18. Barbosa, M.; Borsarelli, C.; Mercadante, A. Light stability of spray-dried bixin encapsulated with different edible polysaccharide preparations. Food Res. Int. 2005, 38, 989-994. [CrossRef]

19. Swain, T.; Hillis, W.E. The phenolic constituents of Prunus domestica. I.-The quantitative analysis of phenolic constituents. J. Sci. Food Agric. 1959, 10, 63-68. [CrossRef]

20. FAO/WHO. Compendium of Food Additive Specifications; FAO: Rome, Italy, 2006; Volume 67, pp. 3-4, ISBN 9251055599.

21. Contreras-Calderón, J.; Calderón-Jaimes, L.; Guerra-Hernández, E.; García-Villanova, B. Antioxidant capacity, phenolic content and vitamin $\mathrm{C}$ in pulp, peel and seed from 24 exotic fruits from Colombia. Food Res. Int. 2011, 44, 2047-2053. [CrossRef]

22. Benzie, I.F.F.; Strain, J. The Ferric Reducing Ability of Plasma (FRAP) as a Measure of "Antioxidant Power": The FRAP Assay. Anal. Biochem. 1996, 239, 70-76. [CrossRef] [PubMed]

23. Nurhuda, H.H.; Maskat, M.Y.; Mamot, S.; Afiq, J.; Aminah, A. Effect of blanching on enzyme and antioxidant activities of rambutan (Nephelium lappaceum) peel. Int. Food Res. J. 2013, 20, 1725-1730.

24. Quanhong, L.; Caili, F. Application of response surface methodology for extraction optimization of germinant pumpkin seeds protein. Food Chem. 2005, 92, 701-706. [CrossRef]

25. Sinha, K.; Chowdhury, S.; Saha, P.D.; Datta, S. Modeling of microwave-assisted extraction of natural dye from seeds of Bixa orellana (Annatto) using response surface methodology (RSM) and artificial neural network (ANN). Ind. Crops Prod. 2013, 41, 165-171. [CrossRef] 
26. Da Costa, C.L.S.; Chaves, M.H. Extração de pigmentos das sementes de Bixa orellana L.: Uma alternativa para disciplinas experimentais de química orgânica. Quim. Nova 2005, 28, 149-152. [CrossRef]

27. Novoa Vidal, A.; Motidome, M.; Mancini-filho, J.; Linares Fallarero, A.; Tanae, M.; Torres Brando, M.L.; Lapa, A.J. Actividad antioxidante y ácidos fenólicos del alga marina Bryothamnion triquetrum (S.G. Gmelim) Howe. Rev. Bras. Cienc. Farm. 2001, 37, 373-382.

28. Rubio-Senent, F.; Fernández-Bolaños, J.; García-Borrego, A.; Lama-Muñoz, A.; Rodríguez-Gutiérrez, G. Influence of $\mathrm{pH}$ on the antioxidant phenols solubilised from hydrothermally treated olive oil by-product (alperujo). Food Chem. 2017, 219, 339-345. [CrossRef] [PubMed]

29. Zhang, L.L.; Xu, M.; Wang, Y.M.; Wu, D.M.; Chen, J.H. Optimizing ultrasonic ellagic acid extraction conditions from infructescence of platycarya strobilacea using response surface methodology. Molecules 2010, 15, 7923-7932. [CrossRef]

30. Yolmeh, M.; Habibi-najafi, M.B.; Shakouri, S.; Hosseini, F.; Resource, N.; Branch, S. Comparing Antibacterial and Antioxidant Activity of Annatto Dye Extracted by Conventional and Ultrasound-Assisted Methods. Zahedan J. Res. Med. Sci. 2015, 17, 29-33. [CrossRef]

(C) 2019 by the authors. Licensee MDPI, Basel, Switzerland. This article is an open access article distributed under the terms and conditions of the Creative Commons Attribution (CC BY) license (http://creativecommons.org/licenses/by/4.0/). 